\title{
ANALYSIS OF CRITICAL DISASTERS IN BULGARIA BASED ON THEIR CLASSIFICATION
}

\section{Iskra Simova ${ }^{1}$, Tsvetelina Petrova $^{2}$, Rositsa Velichkova $^{3}$, Detelin Ganchev Markov ${ }^{4}$, Milka Uzunova ${ }^{5}$, Martin Pushkarov ${ }^{6}$}

\begin{abstract}
Disasters caused by natural phenomena or human activities often occur in the Republic of Bulgaria. Their social and economic consequences can have a significant adverse effect on the development of the country and its economic growth, therefore disaster risk reduction is very important for sustainable development. This paper presents an overview of the main natural and man-made hazards in Bulgaria. A descriptive analysis of the critical disasters in Bulgaria for the time periods of 2003-2008 and 2010-2016 is made. The survey is based on the classification of the hazards. Existing statistical data is reviewed and analysed and, as a consequence, recommendations are proposed.
\end{abstract}

UDC Classification: 502; DOI: http://dx.doi.org/10.12955/cbup.v6.1315

Keywords: critical disaster, statistical data, analysis, results

\section{Introduction}

In the coming decades, climate change is expected to lead to an increase in the frequency and magnitude of disasters. More frequent and stronger storms and floods, as well as long-term droughts and devastating forest fires, can have a significant negative impact on society's existing capabilities after such dangerous events.

For this reason, and due to the complexity and scale of disasters, it is necessary to pool the efforts of all responsible institutions and actively to involve them in disaster risk reduction activities, which is expected to lead to a significant reduction in human, social, economic and natural damage and losses.

In recent years, disaster risk reduction has become a global priority. Evidence is provided by the documents adopted by the European Union (EU) member states, as well as the UN Framework for Action 2005-2015 "Building Sustainability of Nations and Societies for Disasters", which invite and designate each country as responsible to create a National Platform and Disaster Risk Reduction Strategy.

The aim of the present work is to analyse the possible natural disasters in the territory of the Republic of Bulgaria for the period 2003-2008 and 2010-2015 on the basis of their classification.

\section{Possible hazards in the Republic of Bulgaria.}

The Republic of Bulgaria is exposed to the following types of hazards:

Seismic hazards

Seismic impacts are characterized by their unpredictability, especially in terms of time, which causes large-scale negative consequences - victims and injuries of the population, material and economic damage and etc. From a seismological point of view Bulgaria is located in the Alps-Himalayan seismic zone, characterized by high seismicity.

Danger from floods

Floods are a common natural disasters in the territory of the Republic of Bulgaria. They can do enormous damage as they affect urban territories, productive agricultural land and forests. According to the scientific classification for this type of hazard and according to the Water Act, floods can be

\footnotetext{
${ }^{1}$ Technical University of Sofia, Department Hydroaerodynmics and hydraulic machines, Bulgaria, iskrasimova@gmail.com

${ }^{2}$ College of Energy and Electronics (CEE), Department of Energy and Mechanical Engineering, Bulgaria, tzvetelina.petrova@tu-sofia.bg

${ }^{3}$ Technical University of Sofia, Department Hydroaerodymaics and hydraulic machines, Bulgaria, rositsavelichkova@abv.bg

${ }^{4}$ Technical University of Sofia, Department Hydroaerodymaics and hydraulic machines, Bulgaria, detmar@abv.bg

${ }^{5}$ ECAM-EPMI, LR2A.Lab, France, m.uzunova@ecam-epmi.fr

${ }^{6}$ Technical University of Sofia, Department Hydroaerodynmics and hydraulic machines, Bulgaria, martotoo@abv.bg
} 
natural and technological - caused by other influences, such as damage to a hydro technical facility, which can lead to accidents that can cause critical situations in hydro technical facilities.

Floods over the last few years have shown that risk reduction activities for floods that have been applied so far are not sufficient and a policy of comprehensive flood risk management should be put in place under coexistence conditions. Such a complex approach - flood risk assessment and management is enshrined in the European Floods Directive, which was adopted in 2007.

Danger of landslides

The territory of the Republic of Bulgaria is characterized by a high degree of landslide and erosionabrasion activity. Large scale landslides, collapses, abrasion and other unfavourable geodynamic processes have been manifested, which act steadily and destructively. They are difficult to predict, and they occur suddenly. With their unpredictability they threaten the security of settlements, resorts, residential areas, commercial and industrial buildings and technical infrastructure

\section{Dangerous from forest fires}

Forest fires are one of the major hazards to the composition, structure and functioning of Bulgarian forest ecosystems. Climate change over the last decade has increased the frequency of forest fires and the size of the affected areas. In the conditions of global warming and drought, it is logical to expect an increase in fire hazards in forest ecosystems

Danger of meteorological phenomena such as drought, strong winds, heavy snowfalls, snow storms, freezing and extreme temperatures

Drought is a consequence of a reduction in precipitation over a long period of time. Often a number of meteorological elements such as high temperatures, strong winds and low relative humidity coexist with drought, which makes this phenomenon more pronounced. A number of drought indicators in the atmosphere and on the ground should be observed operationally to determine the extent of drought and its impact.

Strong winds in the country can lead to power cuts, road blocking, infrastructure violations and a threat to people's lives and property.

Snow storms and icy conditions cause problems with air traffic communications, road blocks and may put many lives at risk. Snowfalls can be disastrous mainly in settlements and cause not only traffic blockages and interruptions in electricity and water supplies, but also block medical and food supply to the population.

Low temperatures cause icing of power lines and other open communication lines. Annually, about $50-60 \%$ of the country is affected by snowfall and ice.

Extreme temperatures can also be related to natural disasters. On the one hand there are anomalously low temperatures in the spring, autumn and winter periods, on the other there are anomalously high temperatures in the summer - heat.

Danger from nuclear or radiation accidents

Radioactive contamination could occur both in an emergency situation at NPP "Kozloduy", with the release of radionuclides into the environment as well in case of transboundary radioactive contamination due to a nuclear or radiation accident in other countries, as well as in incidents with transport (cars, railway wagons, craft and aircraft) carrying radioactive materials.

In recent years, there has also been a worrying tendency to increase attempts to exploit radioactive sources for terrorist purposes. In this regard, as well as the implementation of the EU Action Plan to Strengthen Anti-Terrorism Threats related to chemical, biological, radioactive and nuclear materials of 2009 has been to create an inter-ministerial working group of experts from the Republic of Bulgaria.

Danger of industrial accidents and accidents when transporting hazardous substances, materials and waste.

On the territory of the Republic of Bulgaria there are companies classified and registered as "high-risk enterprises" as well as "low-risk enterprises", according to the requirements of the Environmental Protection Act and the Ordinance for the Prevention of Major Accidents with Hazardous Substances which mitigate their consequences. These are mainly enterprises involved in the chemical, explosive manufacturing and trade for petroleum and petroleum products and gas industries. 
Major industrial accidents often have severe consequences for the population and the environment, and their impact may also affect territories beyond national borders. This underlines the need to improve existing control of major industrial accident hazards involving dangerous substances and taking appropriate preventive actions to ensure a high level of protection in the Republic of Bulgaria for the population and the environment

Danger of biological contamination

The existing production and economic conditions, the structure of agriculture, the geographical location of the country, the worsening international epizootic and epiphytic situation, the trade, import and export of live animals, products of animal and plant origin are conditions for the occurrence of outbreaks of biological contamination.

The boundaries of a biological outbreak is determined by specialized anti-epidemic and anti-epizootic formations of the competent veterinary authorities, which under certain conditions act in a synchronized way, and those of the affected plants are determined by the phytosanitary inspectors of the Bulgarian Agency for Food Safety.

Danger of hailstorms

As an atmospheric phenomenon, hailstorms cause sensitive losses in agrarian production. At the same time they cause great material damage to the building stock and the farm buildings, and often lead to the loss of human life. The most dangerous hailstorms are rural storms, where the damage to crops in fields is $50-100 \%$ (National plan for protection of hazards, 2010).

\section{Classification of possible natural disasters in the Republic of Bulgaria}

The classification of natural disasters in Bulgaria is given in Table 1. A detailed classification of natural disasters as a whole at a global level is given in our work (R.Velichkova and all,2017).

\begin{tabular}{|c|c|c|}
\hline Disaster Group & Disaster Subgroup & Disaster Main Type \\
\hline \multirow{14}{*}{ Natural } & \multirow[t]{2}{*}{ Geophysical } & Earthquake \\
\hline & & Mass Movement \\
\hline & \multirow[t]{5}{*}{ Meteorological } & Extreme temperature \\
\hline & & Fog \\
\hline & & Snow storm \\
\hline & & Storm \\
\hline & & Hail \\
\hline & \multirow[t]{2}{*}{ Hydrological } & Flood \\
\hline & & Landslide \\
\hline & \multirow[t]{2}{*}{ Climatological } & Drought \\
\hline & & Wildfire \\
\hline & \multirow[t]{3}{*}{ Biological } & Epidemic \\
\hline & & Insect invasion \\
\hline & & Animal Accident \\
\hline \multirow[t]{14}{*}{ Technological } & \multirow[t]{7}{*}{ Industrial accident } & Chemical spill \\
\hline & & Collapse \\
\hline & & Explosion \\
\hline & & Fire \\
\hline & & Gas leak \\
\hline & & Poisoning \\
\hline & & Radiation \\
\hline & \multirow[t]{4}{*}{ Transport accident } & Air \\
\hline & & Road \\
\hline & & Rail \\
\hline & & Water \\
\hline & \multirow[t]{3}{*}{ Miscellaneous accident } & Collapse \\
\hline & & Explosion \\
\hline & & Fire \\
\hline
\end{tabular}




\section{Analysis of the possible natural disasters in the territory of the Republic of Bulgaria}

On the basis of statistics from the National Statistical Institute an analysis of the possible natural disasters in Bulgaria is made according to the classification in Table 1 for the period 2003-2008 year and the period 2010-2015 year.

Figures 1 and 2 show the total number of disasters in the territories in Republic of Bulgaria for the periods of 2003-2008 and 2010-2015.

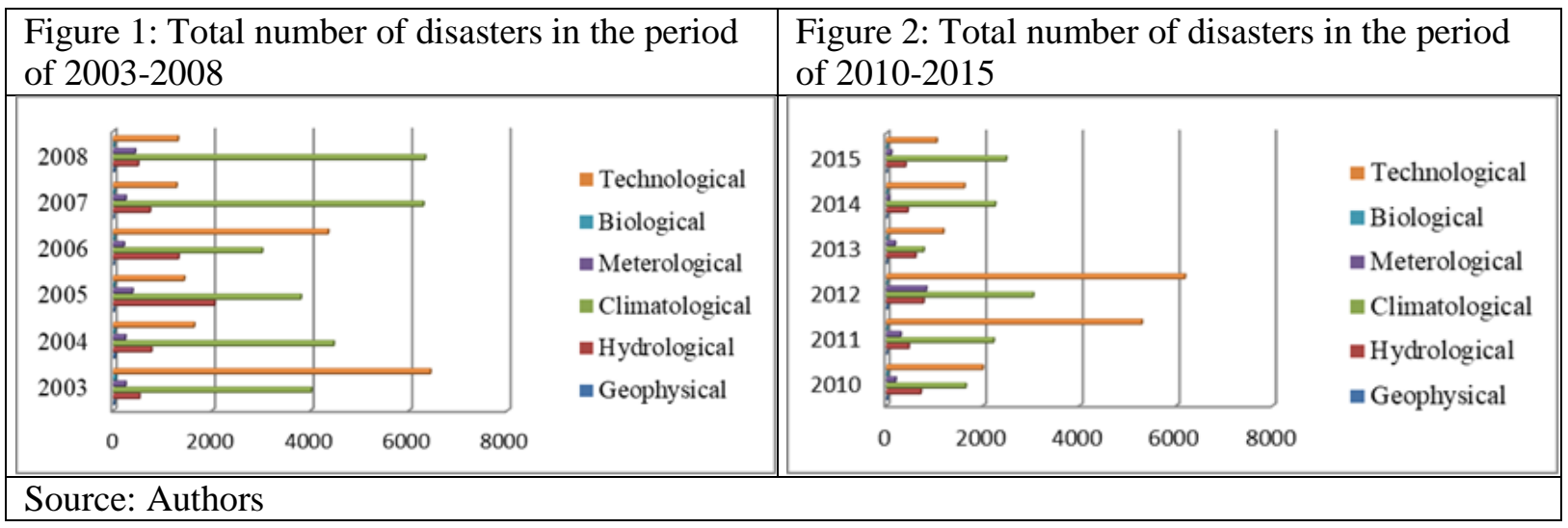

From Figure 1 it can be seen that the predominant disaster in this period is climatological especially for 2007-6287 and 2008-6324. In addition, there are a large number of technological disasters especially for 2003-6431.

From Figure 2 it can be seen that the predominant disasters in this period are technological especially for 2012-6177 and 2011-5284. The second one is again climatological especially for 2012-3033. From this analysis we can say that the disasters are increasing in the period 2010-2015 by almost three times.

The percentage for each disaster for both periods is given in Table 2 .

Table 2:

\begin{tabular}{|c|c|c|}
\hline \multirow{2}{*}{ Type of disasters } & \multicolumn{2}{|c|}{ Percentage, \% } \\
\cline { 2 - 3 } & $2003-2008$ & $2010-2015$ \\
\hline Technological & 34 & 50 \\
\hline Biological & 0.25 & 0.15 \\
\hline Metrological & 3 & 4.5 \\
\hline Climatological & 49.5 & 36 \\
\hline Hydrological & 12.8 & 9 \\
\hline Geophysical & 0.45 & 0.35 \\
\hline Source: Authors
\end{tabular}

Figures 3-8 show the analysis of each group of disasters for the period of 2003-2008.

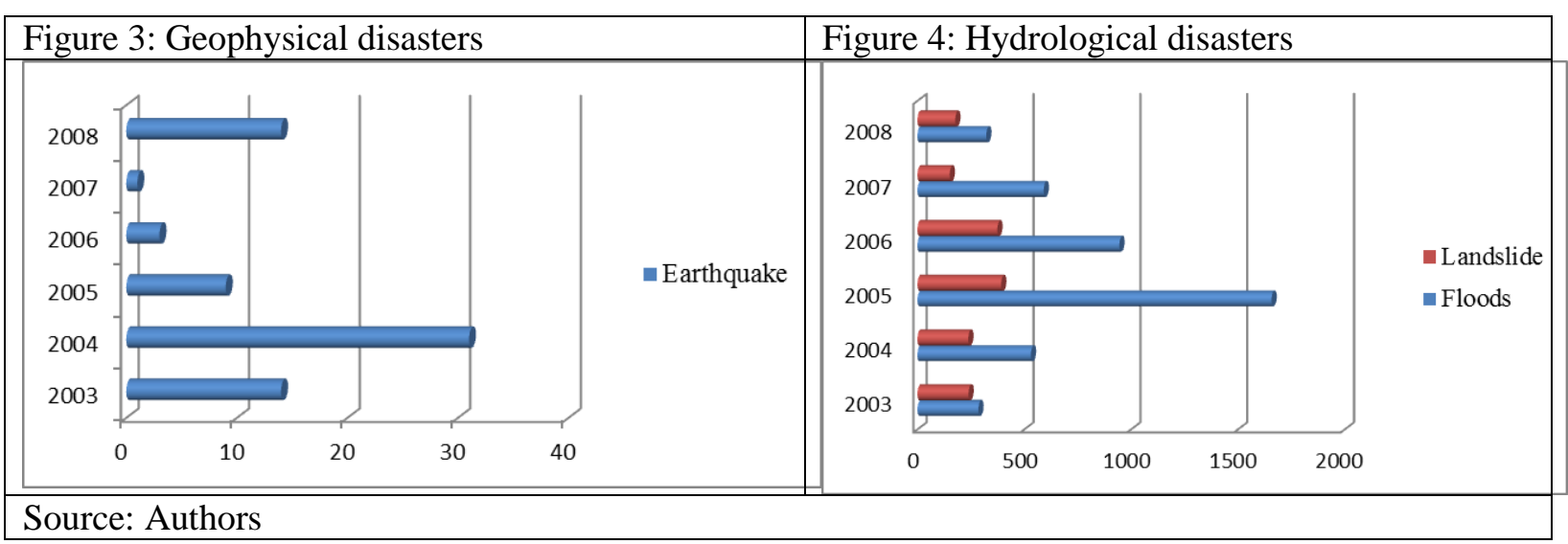




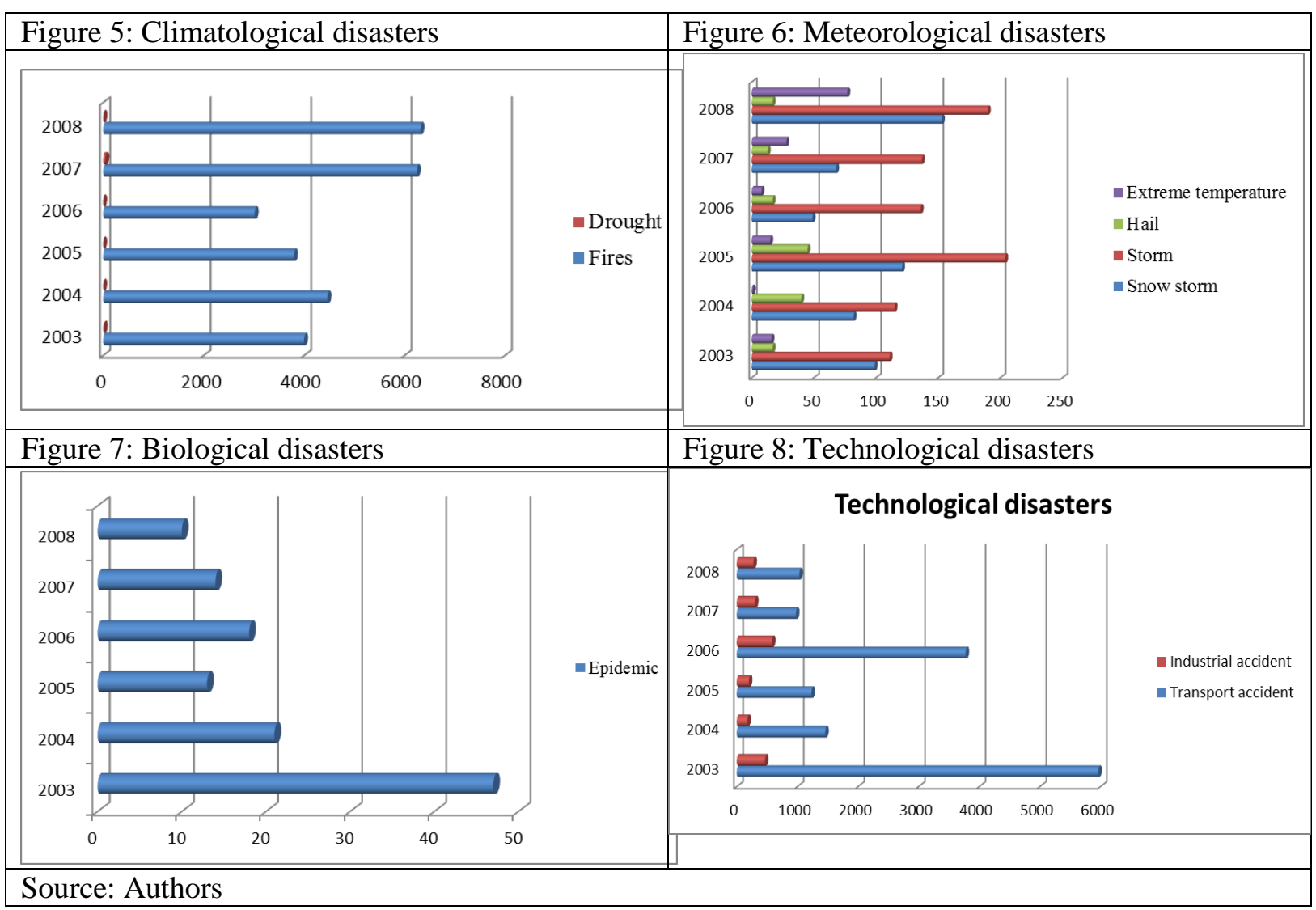

From Figure 3 it can be seen that most earthquakes are in $2004-31$. The percentage of the earthquakes during this period is given in Table 3 .

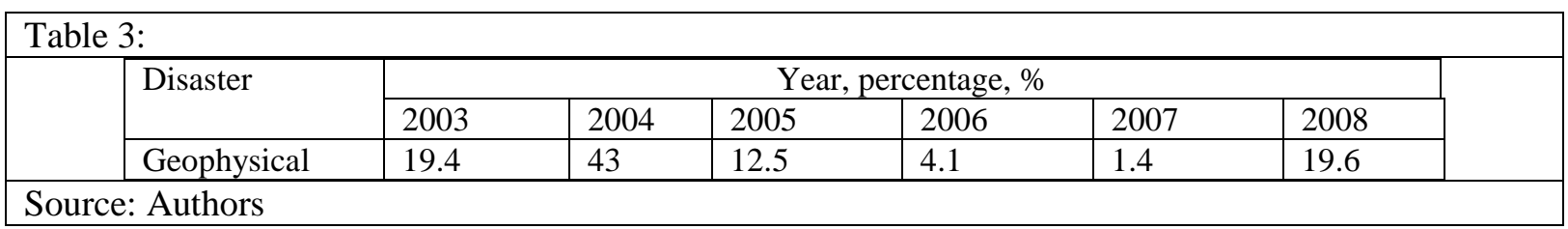

From Figure 4 it can be seen that most hydrological disasters are floods especially in $2005-1657$. The most dangerous year for landslides was 2005-392. The percentage of this group of disasters during this period is given in Table 4.

\begin{tabular}{|l|l|l|l|l|l|l|l|}
\hline \multicolumn{7}{|l|}{ Table 4: } \\
\hline \multirow{3}{*}{} & Disaster & \multicolumn{7}{|c|}{ Year, percentage, \% } \\
\cline { 2 - 8 } & 2003 & 2004 & 2005 & 2006 & 2007 & 2008 \\
\cline { 2 - 7 } & Hydrological & 8.9 & 13 & 34.7 & 4.1 & 22.4 & 8.4 \\
\hline Source: Authors
\end{tabular}

From Figure 5 it can be seen that most climatological disasters are fire especially in $2008-6319$ and 2007- 6245. The most dangerous year for drought was 2007- 42. The percentage of this group of disasters during this period is given in Table 5.

\begin{tabular}{|c|c|c|c|c|c|c|}
\hline \multicolumn{7}{|l|}{ Table 5: } \\
\hline \multirow[t]{2}{*}{ Disaster } & \multicolumn{6}{|c|}{ Year, percentage, \% } \\
\hline & 2003 & 2004 & 2005 & 2006 & 2007 & 2008 \\
\hline Climatological & 14.4 & 16 & 13.6 & 10.8 & 22.5 & 22.7 \\
\hline
\end{tabular}

From Figure 6 it can be seen that most meteorological disasters are storms especially in $2005-204$ and 2008- 190. The most dangerous year for extreme temperature was 2008-77, hail at 2005-45, snow storm 2008-153. The percentage of this group of disasters during this period is given in Table 6. 
Table 6:

\begin{tabular}{|l|c|c|c|c|c|c|}
\hline \multirow{2}{*}{ Disaster } & \multicolumn{7}{|c|}{ Year, percentage, \% } \\
\cline { 2 - 7 } & 2003 & 2004 & 2005 & 2006 & 2007 & 2008 \\
\hline Meteorological & 14.4 & 16 & 13.6 & 10.8 & 22.5 & 22.7 \\
\hline
\end{tabular}

Source: Authors

From Figure 7 it can be seen that most epidemic are in $2003-47$. The percentage of epidemic during this period is given in Table 7 .

Table 7:

\begin{tabular}{|l|c|c|c|c|c|c|}
\hline \multirow{2}{*}{ Disaster } & \multicolumn{7}{|c|}{ Year, percentage, \% } \\
\cline { 2 - 7 } & 2003 & 2004 & 2005 & 2006 & 2007 & 2008 \\
\hline Biological & 38,2 & 17 & 10,6 & 14,6 & 11,3 & 8,3 \\
\hline
\end{tabular}

Source: Authors

Figure 8 shows that the most technological disasters are transport accidents especially in $2003-5965$ and 2006- 3776. The most dangerous year for industrial accidents was 2003-581. The percentage of this group of disasters during this period is given in Table 8 .

\begin{tabular}{|c|c|c|c|c|c|c|}
\hline \multirow{2}{*}{ Disaster } & \multicolumn{6}{|c|}{ Year, percentage, $\%$} \\
\hline & 2003 & 2004 & 2005 & 2006 & 2007 & 2008 \\
\hline Technological & 39.11 & 10 & 8.7 & 26.5 & 7.7 & 7.99 \\
\hline
\end{tabular}

Figures 9-14 show the analysis of each group of disasters in the period of 2010-2015.

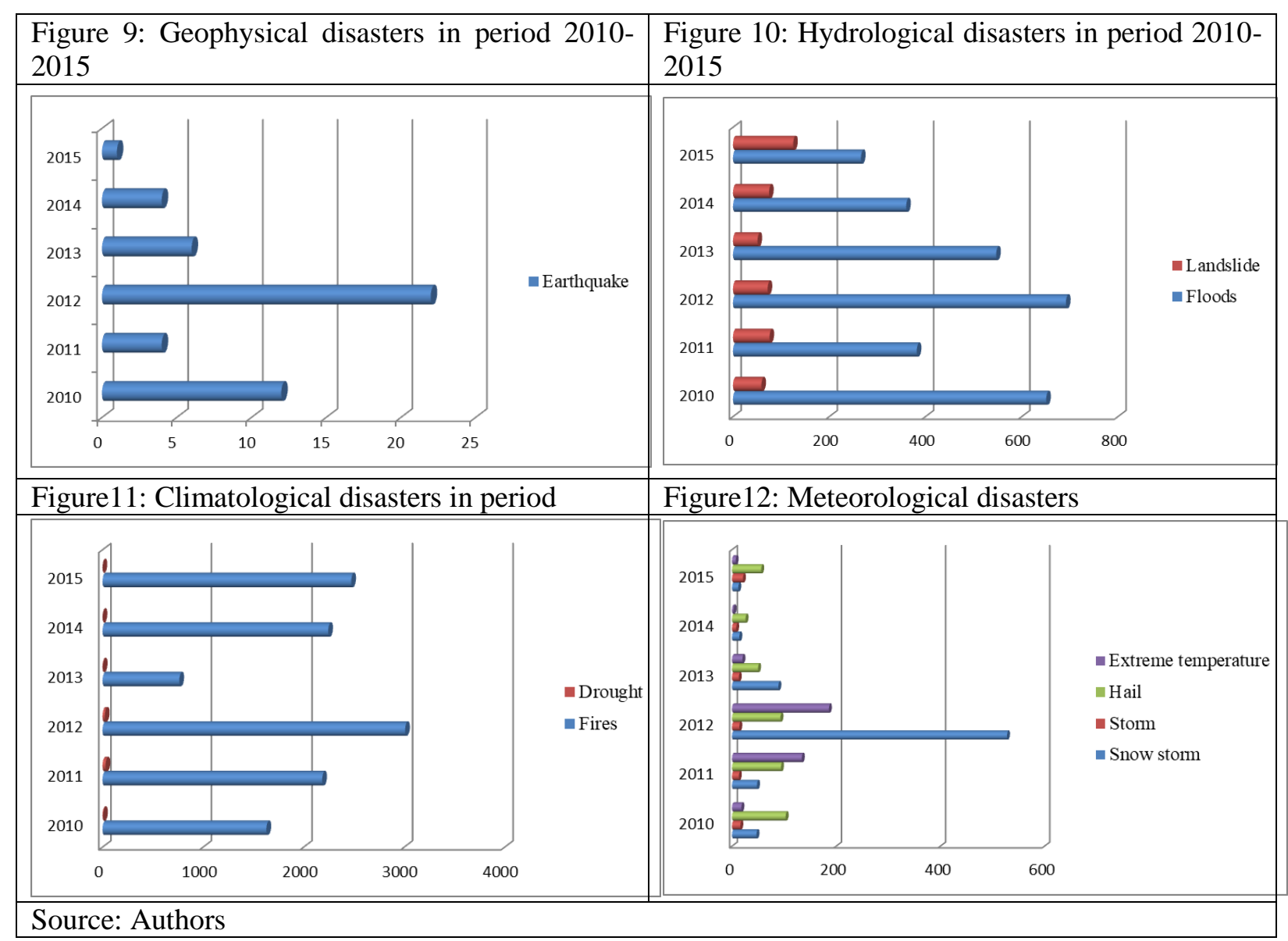




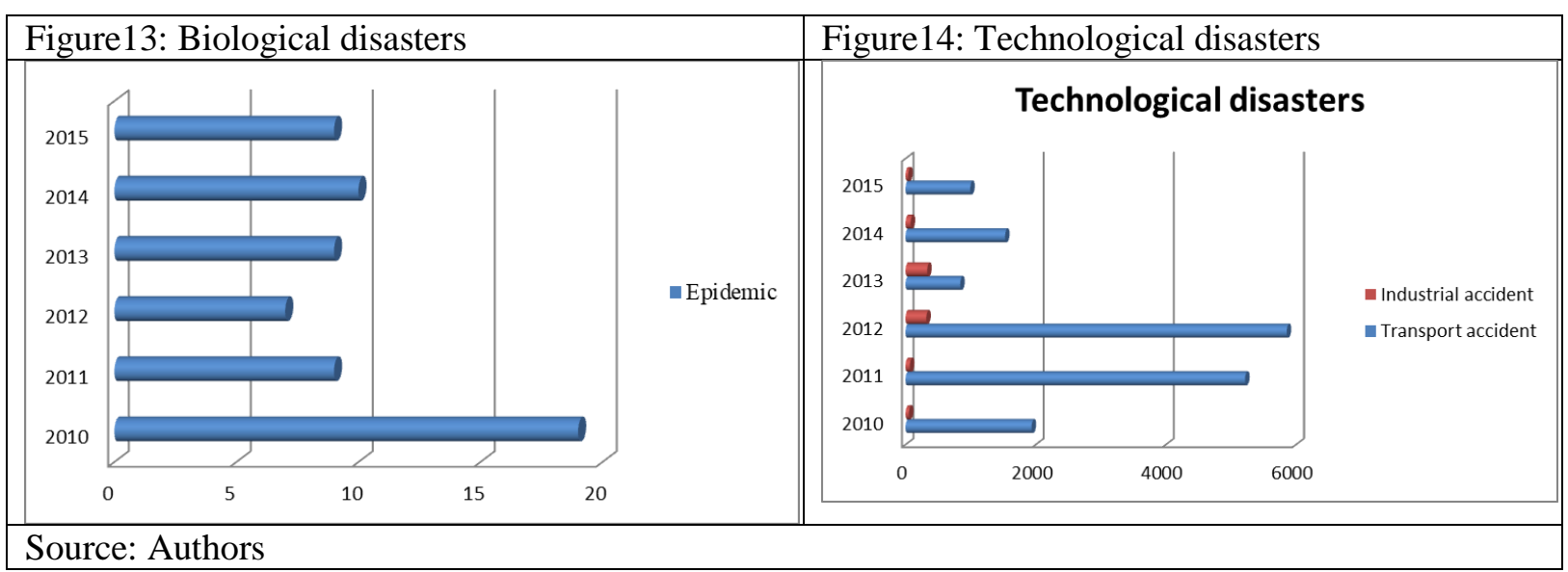

From Figure 9 it can be seen that most earthquakes are in $2012-22$. The percentage of earthquake during this period is give in Table 9.

Table 9:

\begin{tabular}{|c|c|c|c|c|c|c|c|}
\hline & Disaster & & & & entage & & \\
\hline & & 2010 & 2011 & 2012 & 2013 & 2014 & 2015 \\
\hline & Geophysical & 24,5 & 8,16 & 45 & 12.2 & 8.16 & 1.98 \\
\hline
\end{tabular}

From Figure 10 it can be seen that most hydrological disasters are floods especially in $2012-692$ and 2010-651. The most dangerous year for landslide was 2015-125. The percentage of this group of disasters during this period is given in Table 10 .

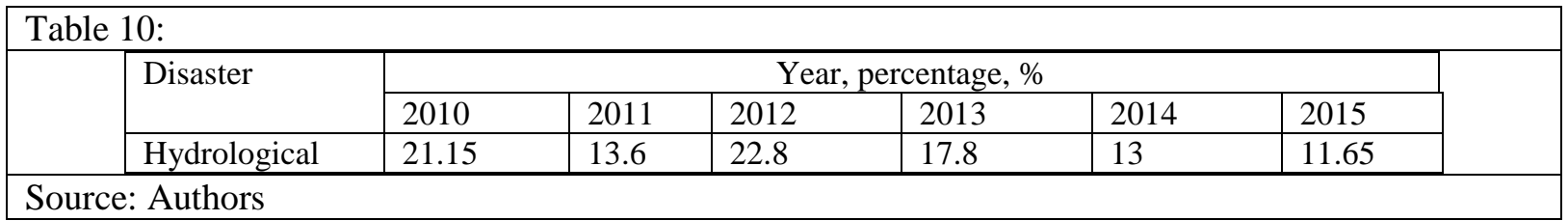

From Figure 11 it can be seen that most climatological disasters are fire especially in $2012-3010$ and 2015- 2474. The percentage of this group of disasters during this period is given in Table 11.

Table 11:

\begin{tabular}{|l|l|l|l|l|l|l|l|}
\hline \multirow{3}{*}{ Disaster } & \multicolumn{7}{|c|}{ Year, percentage, \% } \\
\cline { 2 - 8 } & 2010 & 2011 & 2012 & 2013 & 2014 & 2015 \\
\cline { 2 - 7 } & Climatological & 13.2 & 18 & 24.6 & 6.2 & 18.2 & 19.8 \\
\hline
\end{tabular}

From Figure 12 it can be seen that most meteorological disasters are snow storms especially in 2012 528. The most dangerous year for extreme temperature was 2012-186, hail at 2010-103, storm 201016. The percentage of this group of disasters during this period is given in Table 12.

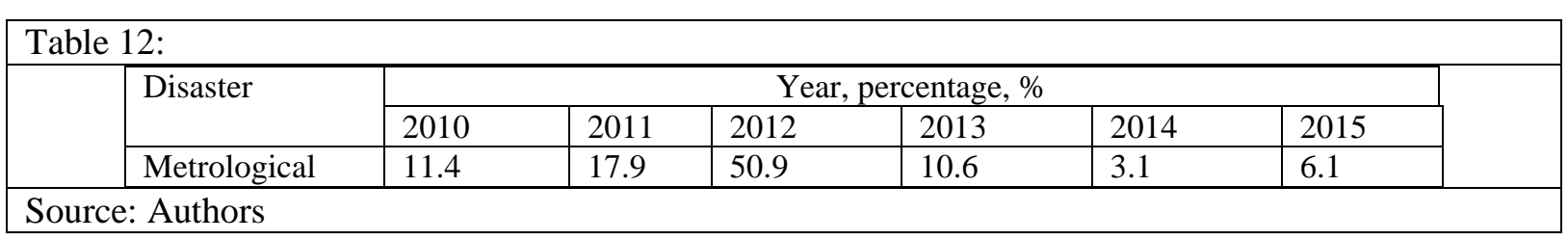

From Figure 13 it can be seen that most epidemic are in 2010 - 19. The percentage of epidemic during this period is given in Table 13 .

\begin{tabular}{|l|l|l|l|l|l|l|l||}
\hline \multicolumn{7}{|l|}{ Table 13: } \\
\hline \multirow{3}{*}{} & Disaster & 2010 & 2011 & 2012 & 2013 & 2014 & 2015 \\
\cline { 2 - 7 } & Biological & 30.1 & 14.3 & 11.1 & 14.3 & 15.9 & 14.3 \\
\hline Source: Authors
\end{tabular}


From Figure 14 it can be seen that most technological disasters are transport accidents especially in 2012 - 5858 and 2011- 5218. The most dangerous year for industrial accidents was 2013-333. The percentage of this group of disasters during this period is given in Table 14.

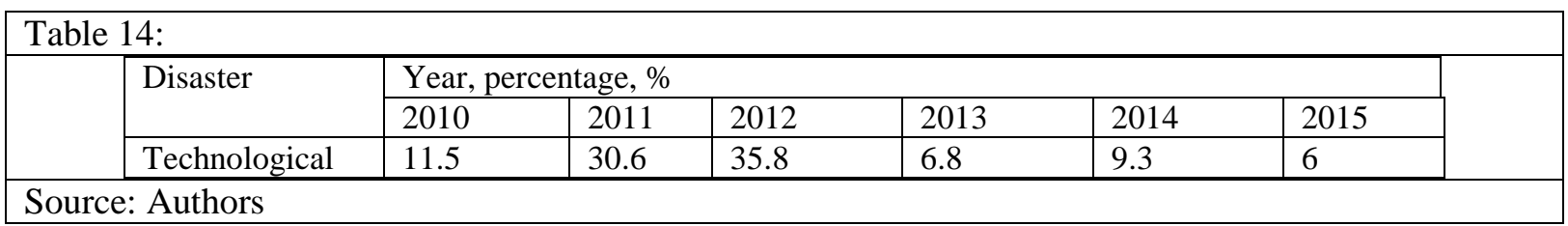

\section{Perspectives}

Disasters caused by natural phenomena or human activities often occur in the Republic of Bulgaria. Their social and economic consequences can have a significant adverse effect on the development of the country and its economic growth, therefore disaster risk reduction is very important for sustainable development.

\section{Conclusion}

In the present work, an analysis of the typical disasters in the territory of Bulgaria for the periods of 2003-2008 and 2010-2015 is made. The analysis is made based on data form the National Statistical Institute in Bulgaria. The number of each disaster during these periods is given in addition to the percentage of disasters in this period. This work can be useful for all stakeholders which are dealing with problem of hazards in Bulgaria.

\section{Acknowledgement:}

The paper is published with the support of the project No BG05M2OP001-2.009-0033 "Promotion of Contemporary Research Through Creation of Scientific and Innovative Environment to Encourage Young Researchers in Technical University - Sofia and The National Railway Infrastructure Company in The Field of Engineering Science and Technology Development" within the Intelligent Growth Science and Education Operational Programme co-funded by the European Structural and Investment Funds of the European Union.

\section{References}

Edward Bryant, (2005),Natural hazards, Second edition, Cambridge University Press

Rositsa Velichkova, Detelin Markov, Iskra Simova, Georgi Burdarov, Tsvetelina Petrova, Zahari Ketipov(2017), On the analysis of natural hazards, Proceeding of Technical University of Sofia, vol.67, issiue3,15-24

National plan for protection of hazards (2010), Council of Ministers, Republic of Bulgaria

National Statistical Institute in Bulgaria www.nsi.bg 